\title{
Article \\ Effects of MOVPE Growth Conditions on GaN Layers Doped with Germanium
}

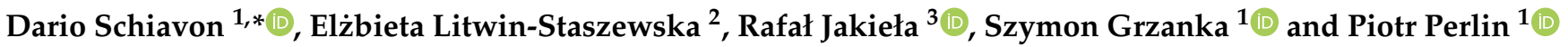 \\ 1 Optoelectronic Devices Laboratory, Institute of High Pressure Physics, Polish Academy of Sciences, \\ al. Sokołowska 29/37, 01-142 Warsaw, Poland; szgrzanka@unipress.waw.pl (S.G.); \\ piotr@unipress.waw.pl (P.P.) \\ 2 Laboratory of Nitride Semiconductor Physics, Institute of High Pressure Physics, Polish Academy of Sciences, \\ al. Sokołowska 29/37, 01-142 Warsaw, Poland; ela@unipress.waw.pl \\ 3 Laboratory of X-ray and Electron Microscopy Research, Institute of Physics, Polish Academy of Sciences, \\ al. Lotników 32/46, 02-668 Warsaw, Poland; jakiela@ifpan.edu.pl \\ * Correspondence: dario.schiavon@unipress.waw.pl
}

\section{check for}

updates

Citation: Schiavon, D.;

Litwin-Staszewska, E.; Jakieła, R.;

Grzanka, S.; Perlin, P. Effects of

MOVPE Growth Conditions on GaN

Layers Doped with Germanium.

Materials 2021, 14, 354. https://

doi.org/10.3390/ma14020354

Received: 24 December 2020

Accepted: 11 January 2021

Published: 13 January 2021

Publisher's Note: MDPI stays neutral with regard to jurisdictional clai$\mathrm{ms}$ in published maps and institutional affiliations.

Copyright: (C) 2021 by the authors. Licensee MDPI, Basel, Switzerland. This article is an open access article distributed under the terms and conditions of the Creative Commons Attribution (CC BY) license (https:// creativecommons.org/licenses/by/ $4.0 /)$.

\begin{abstract}
The effect of growth temperature and precursor flow on the doping level and surface morphology of Ge-doped GaN layers was researched. The results show that germanium is more readily incorporated at low temperature, high growth rate and high V/III ratio, thus revealing a similar behavior to what was previously observed for indium. V-pit formation can be blocked at high temperature but also at low V/III ratio, the latter of which however causing step bunching.
\end{abstract}

Keywords: Ge; germanium; doping; GaN; gallium; nitride; MOVPE; epitaxy

\section{Introduction}

In the last few years there has been a renewed interest in highly doped $n$-GaN layers produced by metal-organic vapor-phase epitaxy (MOVPE). Such layers are very important for the optimization of the operative voltage of GaN-based electronic devices, especially those with tunnel junctions [1], as well as for controlling the layers' refractive index thanks to the plasmonic effect [2]. For all these applications, it is desirable to reach higher doping levels than those achievable with silicon as a donor impurity. In fact, silicon proved inadequate at providing a doping level higher than $10^{19} \mathrm{~cm}^{-3}$ because of a general deterioration of the surface morphology [3] probably caused by the antisurfactant property of Si [4]. Recently, germanium has emerged as a better alternative to silicon as a donor dopant. While it has a similar activation energy $[5,6]$ and provides similar carrier mobility at every doping level [7], germanium has proved capable of attaining doping levels beyond $10^{20} \mathrm{~cm}^{-3}$ without negatively affecting surface morphology $[3,8]$ nor introducing mechanical strain in the epitaxial structure [3,9]. Such a high doping level is sufficient to bring about a decrease of the refractive index of the material, and opens up possibilities of using GaN layers as waveguide claddings in laser structures in place of strained AlGaN layers [2,10].

One problematic aspect of GaN:Ge (i.e., Ge-doped GaN) growth is that the incorporation efficiency of germanium depends strongly on the MOVPE growth conditions. For example, Fritze et al. [3] reported that their dopant precursor flow for germanium was 2-3 orders of magnitude higher than for silicon at the same resulting doping level. Specifically, for a doping level of $1.9 \times 10^{20} \mathrm{~cm}^{-3}$, their Ge/Ga precursor ratio was probably as high as $1 / 3$ in the gas phase. However, Kirste et al. [11] obtained a similar Ge-doping level with a $\mathrm{Ge} / \mathrm{Ga}$ precursor ratio that is two orders of magnitude lower, and therefore quite similar to conventional Si doping. The uncertainty about the incorporation efficiency makes it difficult to control the doping level appropriately, and is therefore an interesting subject of study.

Another challenge of GaN:Ge growth is the difficulty of avoiding the formation of V-pits (hexagonal inverse-pyramidal pits). Such morphological defects have longtime been known to form at low growth temperature, such as in the case of InGaN layers $\left(650-800^{\circ} \mathrm{C}\right)$, 
on top of screw (or mixed) dislocations [12]. During the growth of GaN:Ge layers, however, these can be produced at temperatures as high as $1075^{\circ} \mathrm{C}$ [3], depending possibly also on the concentration of the incorporated germanium. The physical mechanism proposed to explain their formation involves the segregation of liquid germanium droplets on top of screw dislocations. V-pits are then formed as a consequence of the disturbance provoked by the droplets themselves $[13,14]$. Different strategies have been proposed to clear the surface of V-pits, including reducing the density of screw dislocations [3] or, particularly in the case of hydride vapor-phase epitaxy (HVPE), reducing the partial pressure of diatomic hydrogen in the reactor chamber [13].

Until today, there has not yet been a systematic investigation detailing how the growth conditions affect germanium incorporation and V-pit formation. Advanced modeling of the growth of group III-nitride materials based on density-functional theory (DFT) have generally proved to be adequate methods for understanding temperature and precursorflow trends in these layered materials $[15,16]$. This article, however, will focus on presenting direct experimental data. In particular, we will show that germanium incorporation behaves similarly to indium incorporation, suggesting that the underlying physical mechanism is the same. Moreover, we will offer an alternative solution to the issue of V-pit formation based on the deliberate switch to a growth mode that favors step bunching, followed by mechano-chemical polishing (MCP).

\section{Effect of Temperature and TMGa Flow}

A starting series of 10 samples, conveniently labelled with the letters " $a$ "-" $\mathrm{j}$ ", were grown at different temperatures and Ga-precursor flows on sapphire substrates by metalorganic vapor-phase epitaxy (MOVPE) in an Aixtron close-coupled-showerhead reactor. For all samples, the growth pressure was kept at $10 \mathrm{kPa}$, the showerhead gap at $6 \mathrm{~mm}$ and the total gas flow into the reactor at $8 \mathrm{slm}$ using $\mathrm{H}_{2}$ as carrier gas. The precursor gases are ammonia $\left(\mathrm{NH}_{3}\right)$, trimethylgallium (TMGa) and germane $\left(\mathrm{GeH}_{4}\right)$, the latter being supplied from a mix of $10 \% \mathrm{GeH}_{4}$ and $90 \% \mathrm{H}_{2}$ of six-nines purity. For all samples, the $\mathrm{NH}_{3}$ flow was kept at $2 \mathrm{slm}$ and the $\mathrm{GeH}_{4}$ flow at $7.6 \mu \mathrm{mol} / \mathrm{min}$, which is almost the minimum allowed by our dedicated mass-flow controller. The epitaxial structure consists of a 5 - $\mu \mathrm{m}$-thick undoped GaN buffer layer, and a GaN:Ge test layer with thickness in the range 0.5-1.2 $\mu \mathrm{m}$. The growth rate (GR) was monitored by a laser reflectometer and the susceptor surface temperature ( $T$ ) was measured by an Aixtron Argus ${ }^{\mathrm{TM}}$ dual-wavelength pyrometer with emissivity correction. The samples were characterized by secondary-ion mass spectrometry (SIMS) and Van-der-Pauw Hall-effect measurements. The results are summarized in Table 1. Note that not all samples were measured by SIMS, and that sample " $j$ " was highly resistive so it could not be characterized by Hall effect. However, wherever both types of data are available, we see that the electron density matches the germanium concentration within the uncertainty of the SIMS measurement, which is in agreement with the general expectation that germanium dopant is mostly activated at room temperature $[5,6,17]$.

Figure 1 shows the GR and the electron density (from Hall measurements) as a function of temperature. The GR depends on the TMGa flow, of course, but it also depends on the temperature. The GR dependence on the temperature is a known phenomenon that is possibly caused by a combination of parasitic reactions and thermal decomposition. In the context of group III-nitride material epitaxy, parasitic reactions are chemical reactions occurring in the gas phase between $\mathrm{NH}_{3}$ and the metalorganic precursors, and producing nanoparticles that are quickly carried out of the reactor chamber (while the thermophoretic effect keeps them from reaching the growth surface). Such reactions are especially well documented for the growth of AlGaN layers with TMGa and TMAl precursors [18,19], where especially TMAl is prone to react and form $\left[\left(\mathrm{CH}_{3}\right)_{2} \mathrm{AlNH}_{2}\right]_{n}$ oligomers from which the nanoparticles can nucleate [20]. Thermal decomposition, on the other hand, is the reverse reaction of growth itself and is caused by the breaking of the chemical bonds between atoms at the surface of the uppermost layer. It has been observed for $\mathrm{GaN}$ layers and it is known to be greatly enhanced by the presence of $\mathrm{H}_{2}$ in the gas flow [21,22]. 
Table 1. Summary of the growth conditions and characterization results of the first series of samples, where only the growth temperature and the TMGa flow were varied. The [Ge] column shows the concentration of germanium impurities in the test layers as measured by SIMS. The $n$ and $\mu$ columns show the electron density and mobility from the Hall-effect measurements.

\begin{tabular}{ccccccccc}
\hline Id & $\begin{array}{c}T \\
\left({ }^{\circ} \mathbf{C}\right)\end{array}$ & $\begin{array}{c}\text { GR } \\
\left(\frac{\boldsymbol{\mu m}}{\mathbf{h}}\right)\end{array}$ & $\begin{array}{c}\mathbf{N H}_{3} \\
(\mathbf{s l m})\end{array}$ & $\begin{array}{c}\mathbf{T M G a} \\
\left(\frac{\boldsymbol{\mu m o l}}{\mathbf{m i n}}\right)\end{array}$ & $\begin{array}{c}\mathbf{G e H}_{4} \\
\left(\frac{\boldsymbol{\mu m o l}}{\mathbf{m i n}}\right)\end{array}$ & $\begin{array}{c}{[\mathrm{Ge}]} \\
\left(\mathbf{c m}^{-3}\right)\end{array}$ & $\begin{array}{c}n \\
\left(\mathbf{c m}^{-3}\right)\end{array}$ & $\begin{array}{c}\mu \\
\left(\frac{\mathbf{c m}^{2}}{\mathbf{V} \mathbf{s}}\right)\end{array}$ \\
\hline $\mathrm{a}$ & 1008 & 3.09 & 2 & 80 & 7.6 & $3-5 \times 10^{19}$ & $3.9 \times 10^{19}$ & 116 \\
$\mathrm{~b}$ & 1026 & 2.97 & 2 & 80 & 7.6 & & $1.6 \times 10^{19}$ & 145 \\
$\mathrm{c}$ & 1044 & 2.78 & 2 & 80 & 7.6 & & $7.1 \times 10^{18}$ & 187 \\
$\mathrm{~d}$ & 1062 & 2.65 & 2 & 80 & 7.6 & & $4.2 \times 10^{18}$ & 218 \\
$\mathrm{e}$ & 1071 & 2.51 & 2 & 80 & 7.6 & & $2.8 \times 10^{18}$ & 203 \\
$\mathrm{f}$ & 991 & 0.83 & 2 & 25 & 7.6 & & $4.4 \times 10^{19}$ & 153 \\
$\mathrm{~g}$ & 1016 & 0.73 & 2 & 25 & 7.6 & $1-2 \times 10^{19}$ & $1.7 \times 10^{19}$ & 147 \\
$\mathrm{~h}$ & 1037 & 0.60 & 2 & 25 & 7.6 & & $7.3 \times 10^{18}$ & 205 \\
$\mathrm{i}$ & 1008 & 0.19 & 2 & 12 & 7.6 & $1-2 \times 10^{19}$ & $1.1 \times 10^{19}$ & 224 \\
$\mathrm{j}$ & 1014 & 0.05 & 2 & 6 & 7.6 & $3-7 \times 10^{18}$ & & \\
\hline
\end{tabular}

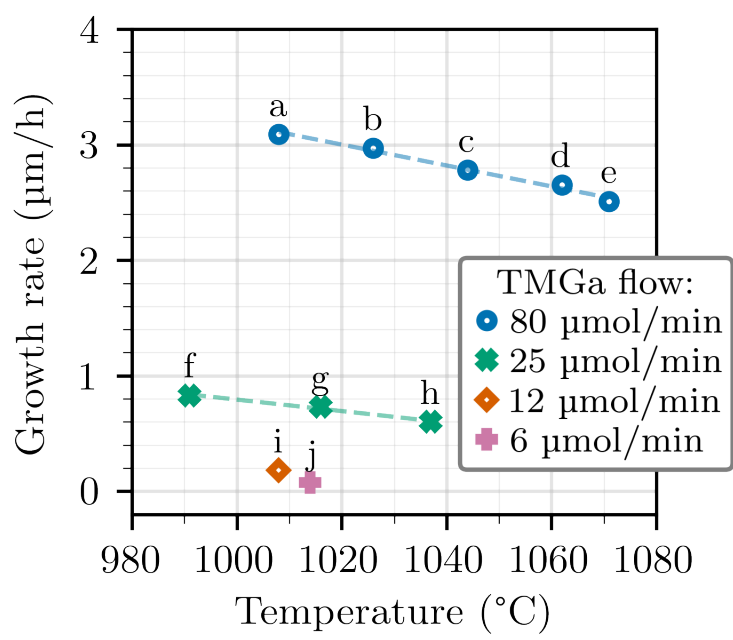

(a)

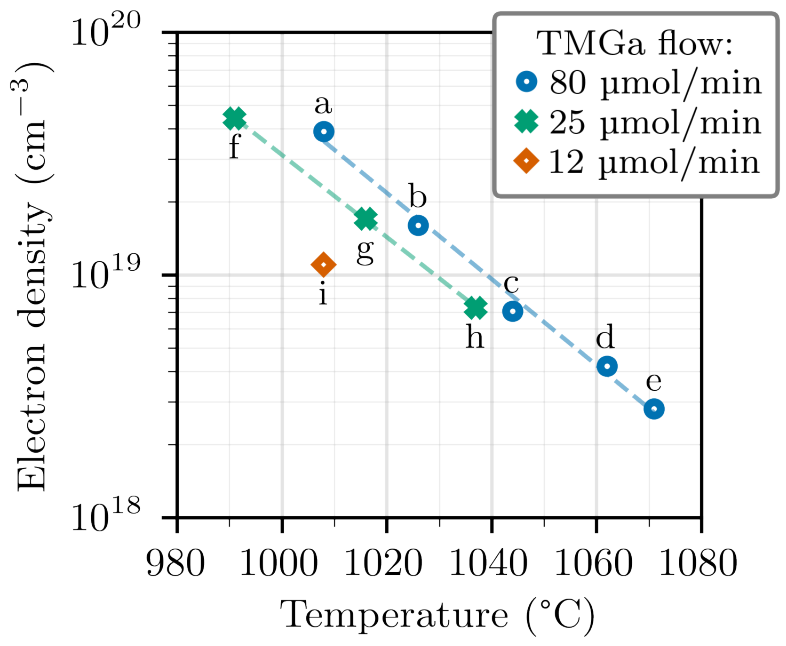

(b)

Figure 1. Growth rate (GR) (a) and electron density (b) for GaN:Ge layers grown at different temperatures and TMGa flows, while the $\mathrm{NH}_{3}$ and $\mathrm{GeH}_{4}$ flows are kept at $2 \mathrm{slm}$ and $7.6 \mu \mathrm{mol} / \mathrm{min}$, respectively. The dashed lines are linear fits to the data.

To better show which mechanism is prevailing in our case, we interpolated the GR corresponding to each TMGa flow at the temperature of $1010^{\circ} \mathrm{C}$. The resulting values are plotted in Figure 2. In addition to the Ge-doped samples, the plot also includes the GR of undoped GaN layers, which were grown in the exact same conditions except that no $\mathrm{GeH}_{4}$ was introduced into the reactor. We note that the GR drops to zero for a TMGa flow close to $7 \mu \mathrm{mol} / \mathrm{min}$, which must be the flow at which the supply of ad-atoms from the precursors matches the loss due to thermal decomposition. This clearly proves that thermal decomposition is taking place. On the other hand, the same data exclude the possibility that parasitic reactions are occurring, because the relation between the GR and the TMGa flow appears to be linear, whereas parasitic reactions would rather result in a drooping curve. We also note that $\mathrm{GeH}_{4}$ does not have a significant influence on either the GR or the decomposition rate, because the corresponding lines on the plot do not have different slopes, nor do they have different intercepts with the $x$-axis. We cannot exclude, however, that parasitic reactions could become relevant at higher $\mathrm{GeH}_{4}$ flow or higher temperature. 


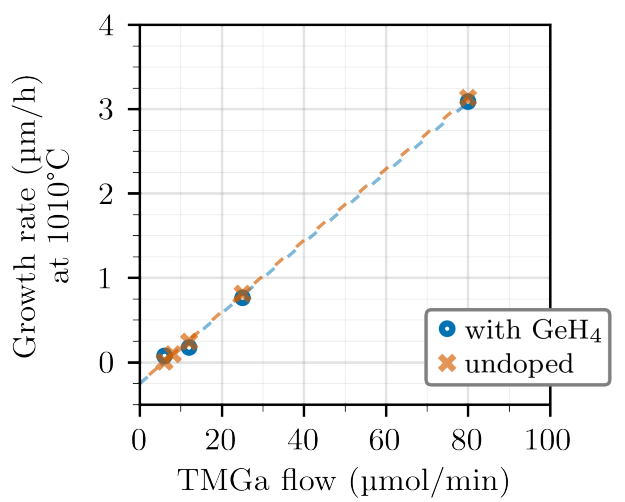

Figure 2. GR of Ge-doped and undoped GaN layers grown at $1010^{\circ} \mathrm{C}$ and different $\mathrm{TMGa}$ flows The GR of the doped layers is interpolated from the data of Figure 1a. Note that the data for doped and undoped layers overlap on the same line and that this line crosses the $x$-axis for a TMGa flow of $7 \mu \mathrm{mol} / \mathrm{min}$.

As for Figure $1 b$, the concentration of germanium atoms in the layers, which we take to be equal to the electron density, is clearly seen to decrease for increasing temperature at each TMGa flow. Moreover, when comparing samples grown with different TMGa flows (but with the same $\mathrm{GeH}_{4}$ flow of $7.6 \mathrm{\mu mol} / \mathrm{min}$ ), the samples grown with the highest TMGa flow turn out to be those with the highest doping level, which is against our expectations, considering that the $\mathrm{Ge} / \mathrm{Ga}$ molar ratio in the gas phase is actually smaller. This contrast starkly from the case of silicon, where the doping level is found to be proportional to 1/GR and mostly independent of the temperature [23]. It means that the incorporation efficiency of germanium, unlike silicon, varies as a function of temperature and GR. In fact, our data indicate that the incorporation of germanium behaves similarly to the incorporation of indium in InGaN layers, which is also more easily incorporated at high GR and low temperature [24]. In the case of indium, this is commonly explained by the fact that indium ad-atoms desorb very easily from the growth surface due to the high vapor pressure of indium over (In) GaN [25]. In the case of germanium, given that we have already excluded the possibility of significant parasitic reactions in these growth conditions, we can presume that the mechanism may be the same as it is for indium. At first, the juxtaposition of germanium and indium may seem odd considering that they belong to two different groups in the periodic table. However, germanium and indium have an additional electron shell with respect to silicon and gallium. This results in longer and weaker bonds with the neighboring atoms, and a higher probability to desorb from the growth surface.

\section{Effect of $\mathrm{GeH}_{4}$ and $\mathrm{NH}_{3}$ Flow}

The following series of samples (labelled " $\mathrm{k}$ "- " $\mathrm{n}$ ", see Table 2) were grown with $\mathrm{NH}_{3}$ flow reduced to $0.5 \mathrm{slm}$ from the previous $2 \mathrm{slm}$. We consider at first samples " $\mathrm{k}$ "-" $\mathrm{m}$ ", which are grown at approximately the same growth temperature of $970-976{ }^{\circ} \mathrm{C}$ but with variable $\mathrm{GeH}_{4}$ flow. Their GR and electron density are shown in Figure 3. It is found that the electron density (and therefore the concentration of incorporated germanium) does not depend linearly on the $\mathrm{GeH}_{4}$ flow, but instead peaks somewhere at about 15-30 $\mu \mathrm{mol} / \mathrm{min}$ and then decreases for increasing $\mathrm{GeH}_{4}$ flow. Even this behavior, where the incorporation of a given species saturates and then starts to decrease for increasing precursor flow, has been observed for indium in InGaN layers [26,27]. In the case of indium, Guo et al. [27] have tentatively explained the decreasing trend after the peak as the effect of parasitic reactions. The same could be true for germanium since, even though we demonstrated that no parasitic reactions happen at the $\mathrm{GeH}_{4}$ flow of $7.6 \mu \mathrm{mol} / \mathrm{min}$, we cannot exclude that parasitic reactions could be happening at the considerably higher flow of $45 \mu \mathrm{mol} / \mathrm{min}$ (despite the slightly lower temperature of $970{ }^{\circ} \mathrm{C}$ ). Assuming that these parasitic reactions involve both $\mathrm{GeH}_{4}$ and TMGa as reagents, they can also explain the reduction of GR that is observed for increasing $\mathrm{GeH}_{4}$ flows in Figure 3a. 
Table 2. Summary of the growth conditions and characterization results of the second series of samples, where the $\mathrm{NH}_{3}$ flow is reduced to $0.5 \mathrm{slm}$. The [Ge] column shows the concentration of germanium impurities in the test layers as measured by secondary-ion mass spectrometry (SIMS). The $n$ and $\mu$ columns show the electron density and mobility from the Hall-effect measurements.

\begin{tabular}{|c|c|c|c|c|c|c|c|c|}
\hline Id & $\begin{array}{c}T \\
\left({ }^{\circ} \mathrm{C}\right) \\
\end{array}$ & $\begin{array}{c}\text { GR } \\
\left(\frac{\mu \mathrm{m}}{\mathrm{h}}\right)\end{array}$ & $\begin{array}{l}\mathrm{NH}_{3} \\
(\mathrm{~s} \operatorname{lm})\end{array}$ & $\begin{array}{l}\text { TMGa } \\
\left(\frac{\mu \mathrm{mol}}{\mathrm{min}}\right)\end{array}$ & $\begin{array}{c}\mathrm{GeH}_{4} \\
\left(\frac{\mu \mathrm{mol}}{\min }\right)\end{array}$ & $\begin{array}{c}{[\mathrm{Ge}]} \\
\left(\mathrm{cm}^{-3}\right)\end{array}$ & $\begin{array}{c}n \\
\left(\mathrm{~cm}^{-3}\right)\end{array}$ & $\begin{array}{c}\mu \\
\left(\frac{\mathrm{cm}^{2}}{\mathrm{Vs}^{2}}\right)\end{array}$ \\
\hline $\mathrm{k}$ & 970 & 0.50 & 0.5 & 25 & 45 & & $1.3 \times 10^{20}$ & 100 \\
\hline 1 & 970 & 0.67 & 0.5 & 25 & 18 & & $1.8 \times 10^{20}$ & 90 \\
\hline $\mathrm{m}$ & 976 & 0.81 & 0.5 & 25 & 7.6 & $6-10 \times 10^{19}$ & $7.6 \times 10^{19}$ & 136 \\
\hline $\mathrm{n}$ & 999 & 0.73 & 0.5 & 25 & 7.6 & & $2.8 \times 10^{19}$ & 148 \\
\hline
\end{tabular}

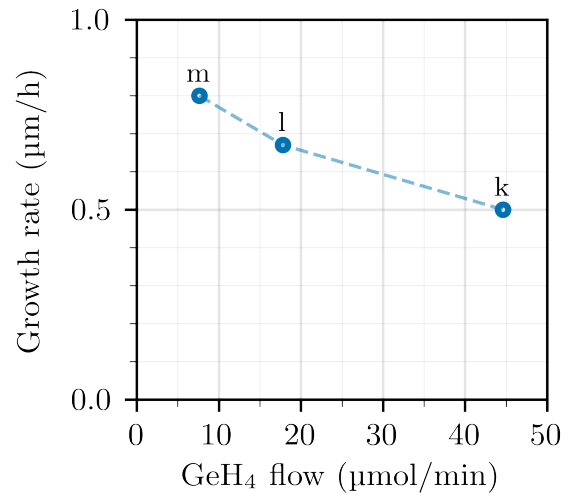

(a)

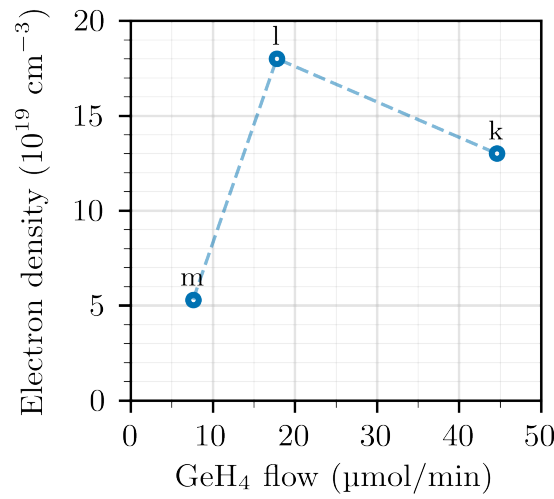

(b)

Figure 3. GR (a) and electrons density (b) for GaN:Ge layers grown at the TMGa flow of $25 \mu \mathrm{mol} / \mathrm{min}$, as a function of $\mathrm{GeH}_{4}$ flow.

It is also useful to compare the samples " $\mathrm{f}$ "- ${ }^{\text {" }} \mathrm{h}$ " from the first series with the samples " $m$ "-" $n$ " from the second series, which are grown with the same TMGa and $\mathrm{GeH}_{4}$ flows but different $\mathrm{NH}_{3}$ flows. Their GR and electron density is shown in Figure 4. Both the GR and the electron density are slightly lower in the second series with respect to the first series, when comparing at the same temperature. The fact that the incorporation of the more volatile group-III species is enhanced at high V/III ratio has also been confirmed for InGaN growth [27].

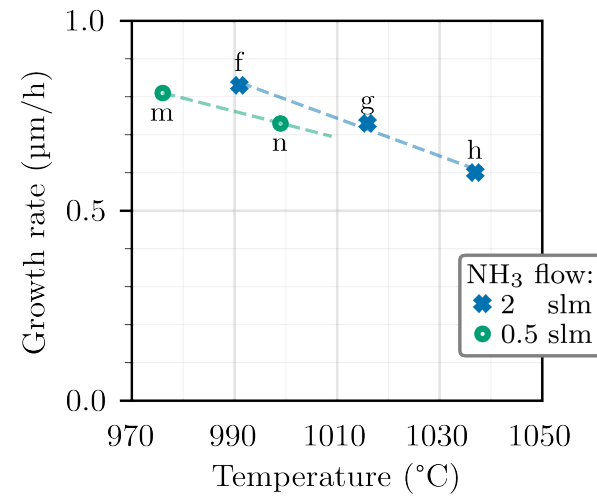

(a)

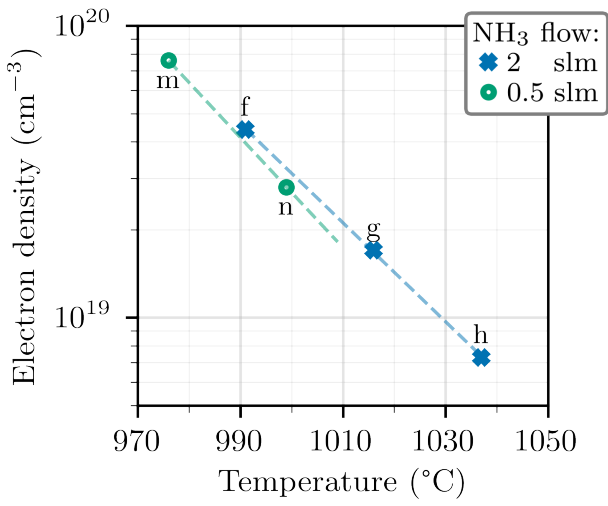

(b)

Figure 4. GR (a) and electrons density (b) in GaN:Ge layers grown at different temperatures and $\mathrm{NH}_{3}$ flows, while the TMGa and $\mathrm{GeH}_{4}$ flows are kept at 26.8 and $7.5 \mu \mathrm{mol} / \mathrm{min}$, respectively. 


\section{Surface Morphology}

A remarkable difference between the first and the second series of samples (grown with a $\mathrm{NH}_{3}$ flow of $2 \mathrm{slm}$ and $0.5 \mathrm{slm}$, respectively) resides in the surface morphology. This was analyzed by optical microscopy and atomic-force microscopy (AFM). The samples of the first series, with the only exception of those grown at temperatures above $1050{ }^{\circ} \mathrm{C}$ (i.e., samples " $\mathrm{d}$ " and " $\mathrm{e}$ "), are characterized by the presence of V-pits with a density of $10^{7} \mathrm{~cm}^{-2}$. The size of the V-pits tends to decrease as the temperature approaches $1050^{\circ} \mathrm{C}$, by which they disappear completely. Unfortunately, as was discussed above, it is not possible to incorporate a satisfactory amount of germanium dopant when growing at temperature higher than $1050^{\circ} \mathrm{C}$. Aside of the V-pits, the surface appears otherwise flat, and growth steps are clearly visible in the AFM scans such as the one shown in Figure 5a.

On the other hand, the samples of the second series are strongly affected by step bunching. Instead of individual atomic steps, fewer but higher macrosteps are observed in AFM scans, as can be seen on sample " $\mathrm{m}$ " shown in Figure $5 \mathrm{~b}$ (for this scan, an area without V-pits was accurately chosen). Moreover, the macrostep height depends on the germanium concentration. Comparing samples " $\mathrm{m}$ " and " $\mathrm{k}$ " in Figure $5 \mathrm{~b}, \mathrm{c}$, one can note that the height of the macrosteps increases as the $\mathrm{GeH}_{4}$ flow is increased from $7.6 \mu \mathrm{mol} / \mathrm{min}$ to $45 \mu \mathrm{mol} / \mathrm{min}$. To make a quantitative comparison possible, sections of all the AFM scans in Figure 5 performed along the $x$-axis are shown in Figure 6 . It can be observed that the macrostep height increases from $8 \mathrm{~nm}$ to $15 \mathrm{~nm}$, corresponding to about 30 and 60 monolayers, respectively. However, no V-pits were found in the samples of the second series. In our experience, the lack of V-pits in samples grown at low temperature is always connected to the emergence of step bunching. Once again, a similar case where the lowering of the $\mathrm{NH}_{3}$ flow produced a significant change of the growth morphology was observed in InGaN layers [28].

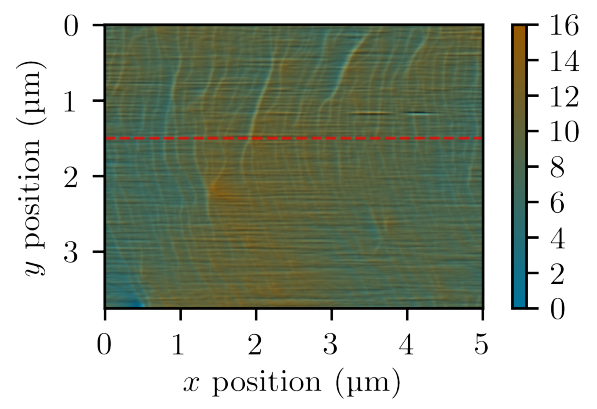

(a) Sample " $\mathrm{f}$ "

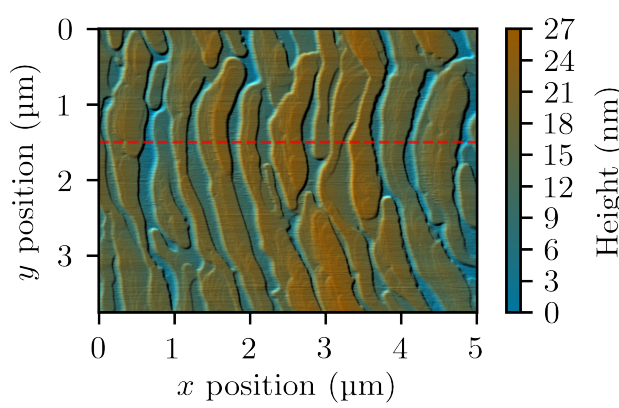

(c) Sample "k"

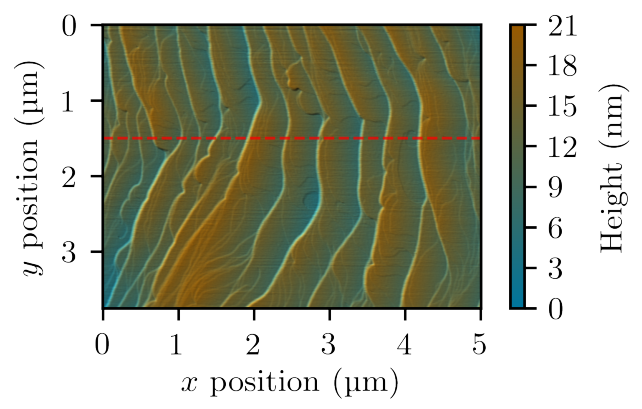

(b) Sample "m"

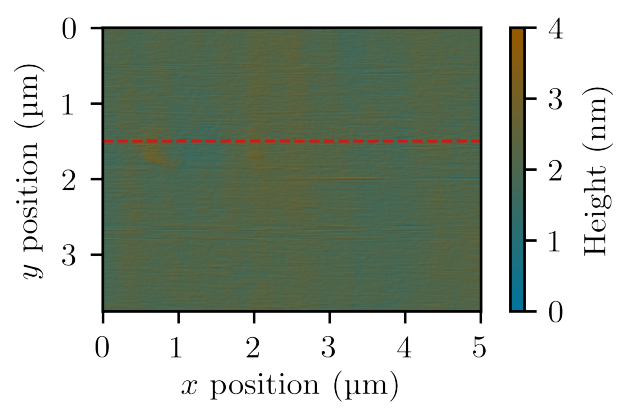

(d) Sample " $\mathrm{m}$ " after MCP

Figure 5. Atomic-force microscopy (AFM) scans of four GaN:Ge layers. Subfigure (d) shows the same sample as subfigure (b) but after mechano-chemical polishing (MCP). The sections marked by the dashed lines are shown in Figure 6. 


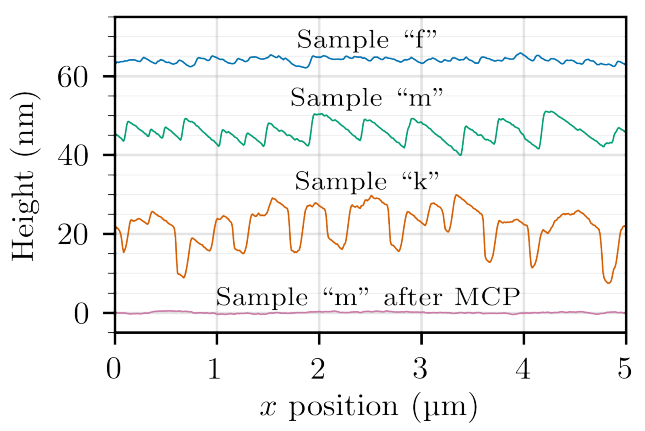

Figure 6. Sections extracted along the dashed lines from the scans shown in Figure 5. The lines have been displaced vertically so that they do not overlap each other.

While step bunching is certainly not a desirable feature by itself, in this case it can prove useful in that it blocks V-pit formation. A good reason to prefer step bunching to V-pits is that the affected layer can be planarized more easily, for example by overgrowing with a high-temperature GaN layer, or by MCP. To prove this, sample " $\mathrm{m}$ " was treated with a 10-min-long MCP process, by which we estimate that approximately $100 \mathrm{~nm}$ were etched. The AFM scan of the resulting flat surface is shown in Figure $5 \mathrm{~d}$. We believe that the same result could likely be obtained with a shorter MCP run as well.

\section{Conclusions}

The effect of growth temperature and precursor flow on germanium incorporation and surface morphology was studied in depth. A total of 14 samples with GaN:Ge layers were grown and characterized. It was found that the germanium incorporation depends on the growth conditions in a similar way to indium incorporation in InGaN layers, namely it increases at low temperature, high growth rate and high V/III ratio, whereas it does not increase linearly with the precursor flow but instead it saturates and then it slowly decreases. The effect of pressure was not tested but, based on the behavior of indium, one can expect that the incorporation of germanium would increase when the pressure is low [29]. Even though our study involved only GaN samples, with caution some conclusions can also be taken for the other group III-nitride alloys. The strong dependence of the germanium incorporation on temperature indicates that germanium may not be the optimal dopant species for Al-rich AlGaN alloys, which are typically grown at high temperature to improve surface ad-atom diffusion $[30,31]$. On the other hand, if the temperature is decreased to the typical values for InGaN growth $\left(650-800^{\circ} \mathrm{C}\right)$, it is possible that germanium's tendency to desorb would cease and its incorporation efficiency would become approximately constant, as it is for silicon at the typical growth conditions for $\mathrm{GaN}\left(950-1050^{\circ} \mathrm{C}\right)$.

The samples of our second series, grown with a reduced $\mathrm{NH}_{3}$ flow, were affected by step bunching but were also free of V-pits. Within the first series, instead, only samples " $\mathrm{d}$ " and " $\mathrm{e}$ " were lacking V-pits, however they also incorporated considerably less germanium because of the high temperature of growth. The macrosteps produced by step bunching are of course undesirable but we showed that they could at least be removed by means of a quick 10-min MCP process. This solution is adequate for structures in which thick GaN:Ge layers are needed, as in the case of the cladding layers of $\mathrm{InGaN} / \mathrm{GaN}$ laser diodes. As for the electron mobility in our GaN:Ge layers, it is about as high as the other values reported in the literature (see Figure 7), so there can be little doubt as to the quality of our samples. 


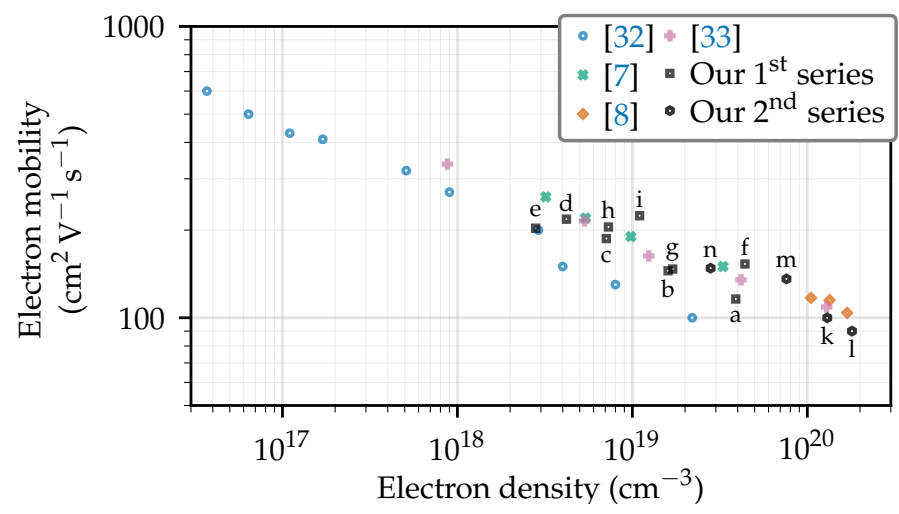

Figure 7. The electron mobility of all samples as a function of the electron density and compared to equivalent values from the literature $[7,8,32,33]$.

Author Contributions: Conceptualization, D.S.; investigation, D.S., E.L.-S. and R.J.; writing, D.S.; project administration, D.S. and S.G.; supervision, P.P. All authors have read and agreed to the published version of the manuscript.

Funding: This work was funded by the Polish National Centre for Science (MINIATURA grant number 2019/03/X/ST5/01907) and the Foundation for Polish Science (grant number TEAM TECH/20174/24).

Institutional Review Board Statement: Not applicable.

Informed Consent Statement: Not applicable.

Data Availability Statement: Data is contained within the article.

Conflicts of Interest: The authors declare no conflict of interest.

\section{References}

1. Arcara, V.F.; Damilano, B.; Feuillet, G.; Vézian, S.; Ayadi, K.; Chenot, S.; Duboz, J.Y. Ge doped GaN and $\mathrm{Al}_{0.5} \mathrm{Ga}_{0.5} \mathrm{~N}-$ based tunnel junctions on top of visible and UV light emitting diodes. J. Appl. Phys. 2019, 126, 224503. [CrossRef]

2. Stanczyk, S.; Czyszanowski, T.; Kafar, A.; Czernecki, R.; Targowski, G.; Leszczynski, M.; Suski, T.; Kucharski, R.; Perlin, P. InGaN laser diodes with reduced AlGaN cladding thickness fabricated on GaN plasmonic substrate. Appl. Phys. Lett. 2013, $102,151102$. [CrossRef]

3. Fritze, S.; Dadgar, A.; Witte, H.; Bügler, M.; Rohrbeck, A.; Bläsing, J.; Hoffmann, A.; Krost, A. High Si and Ge n-type doping of GaN doping_Limits and impact on stress. Appl. Phys. Lett. 2012, 100, 122104. [CrossRef]

4. Markurt, T.; Lymperakis, L.; Neugebauer, J.; Drechsel, P.; Stauss, P.; Schulz, T.; Remmele, T.; Grillo, V.; Rotunno, E.; Albrecht, M. Blocking Growth by an Electrically Active Subsurface Layer: The Effect of Si as an Antisurfactant in the Growth of GaN. Phys. Rev. Lett. 2013, 110, 036103. [CrossRef] [PubMed]

5. Götz, W.; Kern, R.S.; Chen, C.H.; Liu, H.; Steigerwald, D.A.; Fletcher, R.M. Hall-effect characterization of III-V nitride semiconductors for high efficiency light emitting diodes. Mater. Sci. Eng. C 1999, 59, 211-217. [CrossRef]

6. Wang, H.; Chen, A.B. Calculation of shallow donor levels in GaN. J. Appl. Phys. 2000, 87, 7859. [CrossRef]

7. Oshima, Y.; Yoshida, T.; Watanabe, K.; Mishima, T. Properties of Ge-doped, high-quality bulk GaN crystals fabricated by hydride vapor phase epitaxy. J. Cryst. Growth 2010, 312, 3569-3573. [CrossRef]

8. Wieneke, M.; Witte, H.; Lange, K.; Feneberg, M.; Dadgar, A.; Bläsing, J.; Goldhahn, R.; Krost, A. Ge as a surfactant in metal-organic vapor phase epitaxy growth of a-plane GaN exceeding carrier concentrations of $10^{20} \mathrm{~cm}^{-3}$. Appl. Phys. Lett. 2013, 103, 012103. [CrossRef]

9. Nenstiel, C.; Bügler, M.; Callsen, G.; Nippert, F.; Kure, T.; Fritze, S.; Dadgar, A.; Witte, H.; Bläsing, J.; Krost, A.; Hoffmann, A. Germanium-The superior dopant in n-type GaN. Phys. Status Solidi RRL 2015, 9, 716-721. [CrossRef]

10. Perlin, P.; Holc, K.; Sarzyński, M.; Scheibenzuber, W.; Łucja Marona.; Czernecki, R.; Leszczyński, M.; Bockowski, M.; Grzegory, I.; Porowski, S.; Cywiński, G.; Firek, P.; Szmidt, J.; Schwarz, U.; Suski, T. Application of a composite plasmonic substrate for the suppression of an electromagnetic mode leakage in InGaN laser diodes. Appl. Phys. Lett. 2009, 95, 261108. [CrossRef]

11. Kirste, R.; Hoffmann, M.P.; Sachet, E.; Bobea, M.; Bryan, Z.; Bryan, I.; Nenstiel, C.; Hoffmann, A.; Maria, J.P.; Collazo, R.; Sitar, Z. Ge doped GaN with controllable high carrier concentration for plasmonic applications. Appl. Phys. Lett. 2013, 103, 242107. [CrossRef]

12. Kim, I.H.; Park, H.S.; Park, Y.J.; Kim, T. Formation of V-shaped pits in InGaN/GaN multiquantum wells and bulk InGaN films. Appl. Phys. Lett. 1998, 73, 1634. [CrossRef] 
13. Iwinska, M.; Takekawa, N.; Ivanov, V.Y.; Amilusik, M.; Kruszewski, P.; Piotrzkowski, R.; Litwin-Staszewska, E.; Lucznik, B.; Fijalkowski, M.; Sochacki, T.; Teisseyre, H.; Murakami, H.; Bockowski, M. Crystal growth of HVPE-GaN doped with germanium. J. Cryst. Growth 2017, 480, 102-107. [CrossRef]

14. Zhang, Y.; Wang, J.; Su, X.; Cai, D.; Xu, Y.; Wang, M.; Hu, X.; Zheng, S.; Xu, L.; Xu, K. Investigation of pits in Ge-doped GaN grown by HVPE. Jpn. J. Appl. Phys. 2019, 58, 120910. [CrossRef]

15. Santos, R.B.D.; Rivelino, R.; de Brito Mota, F.; Gueorguiev, G.K.; Kakanakova-Georgieva, A. Dopant species with Al-Si and N-Si bonding in the MOCVD of AlN implementing trimethylaluminum, ammonia and silane. J. Phys. D Appl. Phys. 2015, $48,295104$. [CrossRef]

16. Dauelsberg, M.; Talalaev, R. Progress in Modeling of III-Nitride MOVPE. Prog. Cryst. Growth Charact. Mater. 2020, 66, 100486. [CrossRef]

17. Bogusławski, P.; Bernholc, J. Doping properties of C, Si, and Ge impurities in GaN and AlN. Phys. Rev. B 1997, 56, 9496. [CrossRef]

18. Chen, C.H.; Liu, H.; Steigerwald, D.; Imler, W.; Kuo, C.P.; Craford, M.G.; Ludowise, M.; Lester, S.; Amano, J. A study of parasitic reactions between $\mathrm{NH}_{3}$ and TMGa or TMAl. J. Electron. Mater. 1996, 25, 1004-1008. [CrossRef]

19. Ohkawa, K.; Nakamura, K.; Hirako, A.; Iida, D. Influence of polymerization among Al- and Ga-containing molecules on growth rate and $\mathrm{Al}$ content in AlGaN. J. Cryst. Growth 2019, 516, 17-20. [CrossRef]

20. Creighton, J.R.; Wang, G.T. Kinetics of Metal Organic-Ammonia Adduct Decomposition: Implications for Group-III Nitride MOCVD. J. Phys. Chem. A 2005, 109, 10554-10562. [CrossRef]

21. L'vov, B.V. Kinetics and mechanism of thermal decomposition of GaN. Thermochim. Acta 2000, 360, 85-91. [CrossRef]

22. Koleske, D.D.; Wickenden, A.E.; Henry, R.L.; Culbertson, J.C.; Twigg, M.E. GaN decomposition in $\mathrm{H}_{2}$ and $\mathrm{N}_{2}$ at MOVPE temperatures and pressures. J. Cryst. Growth 2001, 223, 466-483. [CrossRef]

23. Koleske, D.D.; Wickenden, A.E.; Henry, R.L.; Twigg, M.E. Influence of MOVPE growth conditions on carbon and silicon concentrations in GaN. J. Cryst. Growth 2002, 242, 55-69. [CrossRef]

24. Piner, E.L.; McIntosh, F.G.; Roberts, J.C.; Boutros, K.S.; Aumer, M.E.; Joshkin, V.A.; El-Masry, N.A.; Bedair, S.M.; Liu, S.X. A Model for Indium Incorporation in the Growth of InGaN Films. Mater. Res. Soc. Symp. Proc. 1997, 449, 85-88. [CrossRef]

25. Matsuoka, T.; Yoshimoto, N.; Sasaki, T.; Katsui, A. Wide-gap semiconductor InGaN and InGaAln grown by MOVPE. J. Electron. Mater. 1992, 21, 157-163. [CrossRef]

26. Ou, J.; Chen, W.K.; Lin, H.C.; Pan, Y.C.; Lee, M.C. An Elucidation of Solid Incorporation of InGaN Grown by Metalorganic Vapor Phase Epitaxy. Jpn. J. Appl. Phys. 1998, 37, L633-L636. [CrossRef]

27. Guo, Y.; Liu, X.L.; Song, H.P.; Yang, A.L.; Xu, X.Q.; Zheng, G.L.; Wei, H.Y.; Yang, S.Y.; Zhu, Q.S.; Wang, Z.G. A study of indium incorporation in In-rich InGaN grown by MOVPE. Appl. Surf. Sci. 2010, 256, 3352-3356. [CrossRef]

28. Oliver, R.A.; Kappers, M.J.; Humphreys, C.J.; Briggs, G.A.D. The influence of ammonia on the growth mode in InGaN/GaN heteroepitaxy. J. Cryst. Growth 2004, 272, 393-399. [CrossRef]

29. Kim, D.J.; Moon, Y.T.; Song, K.M.; Lee, I.H.; Park, S.J. Effect of Growth Pressure on Indium Incorporation During the Growth of InGaN by MOCVD. J. Electron. Mater. 2001, 30, 99-102. [CrossRef]

30. Fujimoto, N.; Kitano, T.; Narita, G.; Okada, N.; Balakrishnan, K.; Iwaya, M.; Kamiyama, S.; Amano, H.; Akasaki, I.; Shimono, K.; Noro, T.; Takagi, T.; Bandoh, A. Growth of high-quality AlN at high growth rate by high-temperature MOVPE. Phys. Status Solidi C 2006, 3, 1617-1619. [CrossRef]

31. Brunner, F.; Protzmann, H.; Heuken, M.; Knauer, A.; Weyers, M.; Kneissl, M. High-temperature growth of AlN in a production scale 11x2" MOVPE reactor. Phys. Status Solidi C 2008, 5, 1799-1801. [CrossRef]

32. Nakamura, S.; Mukai, T.M.T.; Senoh, M.S.M. Si- and Ge-Doped GaN Films Grown with GaN Buffer Layers. Jpn. J. Appl. Phys. 1992, 31, 2883. [CrossRef]

33. Young, N.G.; Farrell, R.M.; Iza, M.; Nakamura, S.; DenBaars, S.P.; Weisbuch, C.; Speck, J.S. Germanium doping of GaN by metalorganic chemical vapor deposition for polarization screening applications. J. Cryst. Growth 2016, 455, 105-110. [CrossRef] 